\title{
ISOLASI SENYAWA METABOLIT SEKUNDER DARI EKSTRAK n-HEKSANA BATANG TUMBUHAN BROTOWALI (Tinosporacrispa L.)
}

\section{ISOLATION OF SECONDARY METABOLITE FROM $\boldsymbol{n}$-HEXANE EXTRACT OF THE STEM OF BROTOWALI (Tinospora crispa)}

\author{
Muharni*, Elfita dan Masyita \\ Jurusan Kimia Fakultas Matematika dan Ilmu Pengetahuan Alam Universitas Sriwijaya \\ *email: muharnimyd@yahoo.co.id
}

\begin{abstract}
ABSTRAK
Telah dilakukan isolasi satu senyawa metabolit sekunder dari ekstrak $n$-heksana batang Tinospora crispa. Ekstraksi dilakukan dengan metode maserasi. Pemisahan dan pemurnian dilakukan dengan teknik kromatografi. Terhadap senyawa hasil isolasi dilakukan uji aktivitas antioksidan menggunakan metode DPPH (1,1 - difenil-2-pikrilhidrazil) dengan variasi konsentrasi 1000, 500, 250, 125, 62,5, 31,25, 15,625 dan 7,8125 $\mu \mathrm{g} / \mathrm{mL}$. Senyawa hasil isolasi diperoleh dalam bentuk minyak berwarna kuning. Berdasarkan data spektroskopi NMR 1D dan dengan membandingkan data senyawa yang telah dilaporkan dari jamur endofitik batang brotowali pada literatur disimpulkan bahwa senyawa hasil isolasi adalah bis-(2-etilheksil)ftalat dengan rumus molekul $\mathrm{C}_{24} \mathrm{O}_{4} \mathrm{H}_{38}$. Uji aktivitas antioksidan dari senyawa hasil isolasi memberikan nilai $\mathrm{IC}_{50}$ sebesar $232,9 \mu \mathrm{g} / \mathrm{mL}$ dan dikategorikan tidak aktif antioksidan.
\end{abstract}

Kata Kunci: Antioksidan, bis-(2-etilheksil)ftalat, Tinospora crispa

\begin{abstract}
Isolation of secondary metabolite from n-hexane extract of the stem of Tinospora crispa had been studied. The extraction was performed by maceration. The extract of $n$ hexane was separated and purified by column chromatography. Antioxidant activity of the isolated compound was conducted by DPPH (1.1-diphenylpycryl hidrazyl) method with concentration variation of $1000,500,250,125,62.5,31.25,15.625$ and $7.8125 \mu \mathrm{g} / \mathrm{mL}$. The isolated compound was a yellow oils. Based on spectroscopy data 1D-NMR and comparing with literature data which had been reported from endophityc fungi of brotowali stem, it was concluded that the isolated compound was bis-(2-ethylhexyl) phthalate with molecular formula $\mathrm{C}_{24} \mathrm{O}_{4} \mathrm{H}_{38}$. The antioxidant activity of the isolated compound showed $\mathrm{IC}_{50} 232.9 \mu \mathrm{g} / \mathrm{mL}$ and was inactive as antioxidant.
\end{abstract}

Keywords: Antioxidant, bis-(2-ethylhexyl) phthalate, Tinospora crispa

\section{PENDAHULUAN}

Tumbuhan brotowali termasuk salah satu spesies dari genus Tinospora yang dikenal dengan nama spesies Tinospora crispa. Tinospora crispa berasal dari India dan kemudian menyebar sampai di Indonesia (Santa dan Bambang, 1998). Tumbuhan brotowali merupakan tumbuhan yang sudah dikenal sebagai tumbuhan obat memar, demam, merangsang nafsu makan, sakit kuning, cacingan, batuk, mencuci luka pada kulit 
atau gatal- gatal dan untuk mengobati penyakit kencing manis. Tumbuhan brotowali dilaporkan memiliki berbagai aktivitas biologis seperti antimalaria, antidiabetes, antipieretik, antihiperglikemik (Noor and Aschroft, 1998). Berdasarkan informasi ilmiah juga telah ditemukan khasiat tumbuhan brotowali yaitu ekstrak batang brotowali yang berpotensi sebagai antioksidan untuk mencegah timbulnya arterioklerosis atau sejenis penyakit kardiovaskuler (Khamarazaman, et al., 2012)

Berdasarkan studi pustaka telah dilaporkan beberapa kandungan kimia dari batang tumbuhan brotowali diantaranya alkaloid kuinolin, alkaloid isokuinolin dan golongan lukosida fenolik (Guo et al., 1999; Hatthakitpanichakul, 2001; Fukuda et al., 1983). Selain itu, pada batang brotowali juga ditemukan senyawa golongan glukosida furanoid diterpen dan senyawa golongan furanoid diterpen (Fukuda et al., 1985; Zambrut et al., 1999). Disamping dari tumbuhannya, pada mikroba endofitik yang terdapat pada batang tumbuhan brotowali dilaporkan pula adanya enam senyawa hasil isolasi antara lain satu senyawa alkaloid (Elfita $e t$ al., 2011), satu senyawa golongan piran (Elfita et al., 2013a, satu senyawa turunan ftalat (Elfita dkk, 2013b) dan satu senyawa turunan lakton (Elfita et al., 2014)

Eksplorasi penelitian brotowali sebagai antioksidan alami telah dilaporkan oleh Irianti, dkk. (2011) di Thailand bahwa ekstrak etanol batang brotowali aktif sebagai antioksidan dengan nilai $\mathrm{IC}_{50}$ sebesar $33 \mu \mathrm{g} / \mathrm{mL}$. Kemudian Cavin (1998) melaporkan n-cis-feruloiltiramin, n-transferuloiltiramin dan sesoisolarikiresinol yang diisolasi dari ekstrak diklorometana batang brotowali menunjukkan aktif sebagai antioksidan. Pada makalah ini akan dilaporkan isolasi dan identifikasi senyawa metabolit sekunder dari ekstrak nheksana batang tumbuhan brotowali (Tinospora crispa L.) dan diuji aktivitas antioksidannya dengan metode DPPH.

\section{METODELOGI}

Alat

Seperangkat alat destilasi, chamber, kromatografi kolom gravitasi, neraca analitis, berbagai peralatan gelas kimia, rotary evaporator R-114 Buchi dengan sistem vakum Buchi B-169, lampu UV CAMAG $254 \mathrm{~nm}$, spektrofotometer NMR JEOL, mortar, botol kaca bervolume 1L.

\section{Bahan}

$\begin{array}{ccc}\text { Batang tumbuhan } & \text { brotowali, } \\ \text { pelarut teknis } & \text { (n-heksan, etilasetat, }\end{array}$ metanol), plat KLT silika gel G60 $\mathrm{F}_{254} 0,25$ mm 20 × $20 \mathrm{~cm}$, silika gel G60 $\mathrm{PF}_{254}$ (70230 mesh), metanol p.a, 1,1-Difenill-2pikrilhidrazil (DPPH), Dimetil Sulfoksida (DMSO), L-Ascorbic Acid Ajax Finechem 99\% (asam askorbat standar).

\section{Persiapan Sampel}

Sampel batang brotowali diperoleh di area Fakultas Keguruan dan Ilmu Pendidikan Universitas Sriwijaya. Sampel batang brotowali segar sebanyak $1 \mathrm{Kg}$ dicuci bersih dengan air dan diangin anginkan hingga kering bagian luarnya. Selanjutnya sampel batang brotowali tersebut ditumbuk sampai hancur secara manual dengan menggunakan alat penggerus mortar.

\section{Ekstraksi Senyawa Metabolit Sekunder}

Batang brotowali (Tinospora crispa L) sebanyak $1 \mathrm{Kg}$ yang sudah digerus dimaserasi menggunakan pelarut nheksana selama 3 hari. Maserasi dilakukan tiga kali pengulangan. Setiap kali pengulangan menggunakan pelarut nheksana dengan volume $1,5 \mathrm{~L}$ untuk sampel batang brotowali sebanyak $1 \mathrm{Kg}$. Filtrat yang diperoleh dipekatkan dengan menggunakan rotary evaporator. Ekstrak pekat n-heksana batang brotowali kemudian dianalisis dengan Kromatografi Lapis Tipis (KLT). 


\section{Pemisahan dan Pemurnian}

Ekstrak pekat n-heksana batang brotowali (5g), kemudian dipisahkan dengan kromatografi kolom gravitasi dengan menggunakan fasa diam silika gel dengan perbandingan 1:10. Sampel dan fasa diam silika gel dilakukan impregnasi terlebih dahulu agar sampel bisa terikat kuat dengan fasa diamnya. Sampel yang sudah diimpregnasi tersebut dimasukkan ke dalam kolom kromatografi secara merata dan dielusi menggunakan eluen sebanyak $50 \mathrm{~mL}$ dengan kepolaran meningkat pada perbandingan n-heksana : etil asetat 10:0 $(50 \mathrm{~mL}), 9: 1(250 \mathrm{~mL}), 8: 2$ (250 mL), 7:3 (300 mL), 6:4 (200 mL), 5:5 $(150 \mathrm{~mL}), 4: 6(150 \mathrm{~mL}), 3: 7(100 \mathrm{~mL})$, $0: 10(50 \mathrm{~mL})$; etilasetat : metanol 5:5 (50 $\mathrm{mL})$ dan metanol $100 \%(50 \mathrm{~mL})$. Eluat ditampung dalam botol vial $10 \mathrm{~mL}$ dan masing-masing dianalisis dengan kromatografi lapis tipis. Eluat dengan pola noda yang sama dikelompokkan menjadi satu fraksi dan diuapkan. Fraksi terpilih kemudian kembali dipisahkan dan dimurnikan dengan teknik kolom gravitasi hingga diperoleh senyawa murni.

\section{Identifikasi Senyawa Hasil Isolasi}

Senyawa murni yang diperoleh ditentukan struktur molekulnya dengan metode spektroskopi NMR 1D $\quad\left({ }^{1} \mathrm{H}-\right.$ $\left.\mathrm{NMR},{ }^{13} \mathrm{C}-\mathrm{NMR}\right)$ dan dibandingkan dengan data senyawa pembanding yang dilaporkan dalam literatur

\section{Uji Aktivitas Antioksidan dengan Metode DPPH}

Pengujian aktivitas antioksidan dilakukan dengan cara $0,2 \mathrm{~mL}$ berbagai konsentrasi larutan sampel $(1000,500$, $250,125,62,5,31,25,15,625$ dan 7,8125 $\mu \mathrm{g} / \mathrm{mL}$ ) ditambahkan 3,8 mL larutan DPPH 0,5 mM. Campuran larutan dihomogenkan dan dibiarkan selama 30 menit di tempat gelap. Serapan diukur dengan spektrofotometer UV-Vis pada $\lambda_{\text {maks }} 517$ nm. Larutan antioksidan standar digunakan asam askorbat standar yang diukur dengan perlakuan yang sama seperti sampel. Aktivitas antoksidan sampel ditentukan oleh besarnya hambatan serapan radikal DPPH melalui perhitungan persentase inhibisi serapan DPPH.

\section{HASIL DAN PEMBAHASAN}

Ekstraksi dari batang brotowali sebanyak $1 \mathrm{Kg}$ didapatkan ekstrak pekat nheksana sebanyak 26 g. Analisis ekstrak dengan teknik KLT dengan penampak noda lampu UV pada $\lambda 254 \mathrm{~nm}$, menunjukkan ekstrak n-heksana berpotensi mengandung senyawa metabolit sekunder. Noda yang menunjukkan warna ungu atau berfluorisensi pada sinar UV mengindikasikan bahwa senyawa metabolit sekunder adalah senyawa yang memiliki beberapa ikatan rangkap yang berkonjugasi atau senyawa aromatik. Ekstrak pekat $n$ heksana batang brotowali (5 g) setelah dipisahkan dengan kromatografi kolom gravitasi didapatkan lima fraksi $F_{1}-F_{5}$. Berdasarkan noda pada KLT fraksi $F_{2}$ sebanyak $1,1 \mathrm{~g}$ menunjukkan adanya pola noda yang dominan dan sederhana sehingga perlu dilakukan pemisahan kembali dengan kolom gravitasi dan berdasarkan pola noda pada KLT diperoleh 3 subfraksi kolom yaitu $F_{2.1}, F_{2.2}$, dan $F_{2.3}$. Subfraksi $F_{2,1}$ memperlihatkan adanya minyak berwarna kuning sebanyak $0,12 \mathrm{~g}$ dan analisis dengan KLT menggunakan eluen $n$-heksana : etilasetat $9,5: 1,5$ dengan penampak noda lampu UV pada $254 \mathrm{~nm}$ menunjukkan pola noda tunggal sehingga diduga senyawa murni.

isolasi dilakukan berdasarkan data spektroskopi; NMR 1 dimensi (1D) yang terdiri dari ${ }^{1} \mathrm{H}$ NMR, dan dibandingkan dengan data senyawa pembanding yang telah dilaporkan pada literatur. Data spektrum ${ }^{1} \mathrm{H}-\mathrm{NMR}$ (Gambar 1) senyawa hasil isolasi menunjukkan adanya sinyal pada daerah $\delta_{\mathrm{H}} 0,90 \mathrm{ppm}(6 \mathrm{H}, t)$ yang merupakan sinyal untuk dua buah gugus metil $\left(\mathrm{CH}_{3}\right)$ yang terkopling oleh proton 
tetangga. Selanjutnya sinyal yang terlihat pada daerah sekitar $\delta_{\mathrm{H}} 1,29-1,43 \mathrm{ppm}$ $(8 \mathrm{H}, m)$ diduga sebagai sinyal untuk gugus-gugus metilen $\left(\mathrm{CH}_{2}\right)$ dalam bentuk alifatik. Pada spektrum ${ }^{1} \mathrm{H}-\mathrm{NMR}$ juga terlihat sinyal pada $\delta_{\mathrm{H}} 1,68 \mathrm{ppm}(1 \mathrm{H}, m)$ yang merupakan suatu proton metin $(\mathrm{CH})$ yang dibelah lebih dari tiga proton tetangga sehingga muncul sebagai sinyal multiplet. Pelebaran spektrum ${ }^{1} \mathrm{H}-\mathrm{NMR}$ pada daerah $\delta_{\mathrm{H}} 0,90-1,69 \mathrm{ppm}$ terlihat pada Gambar 1.
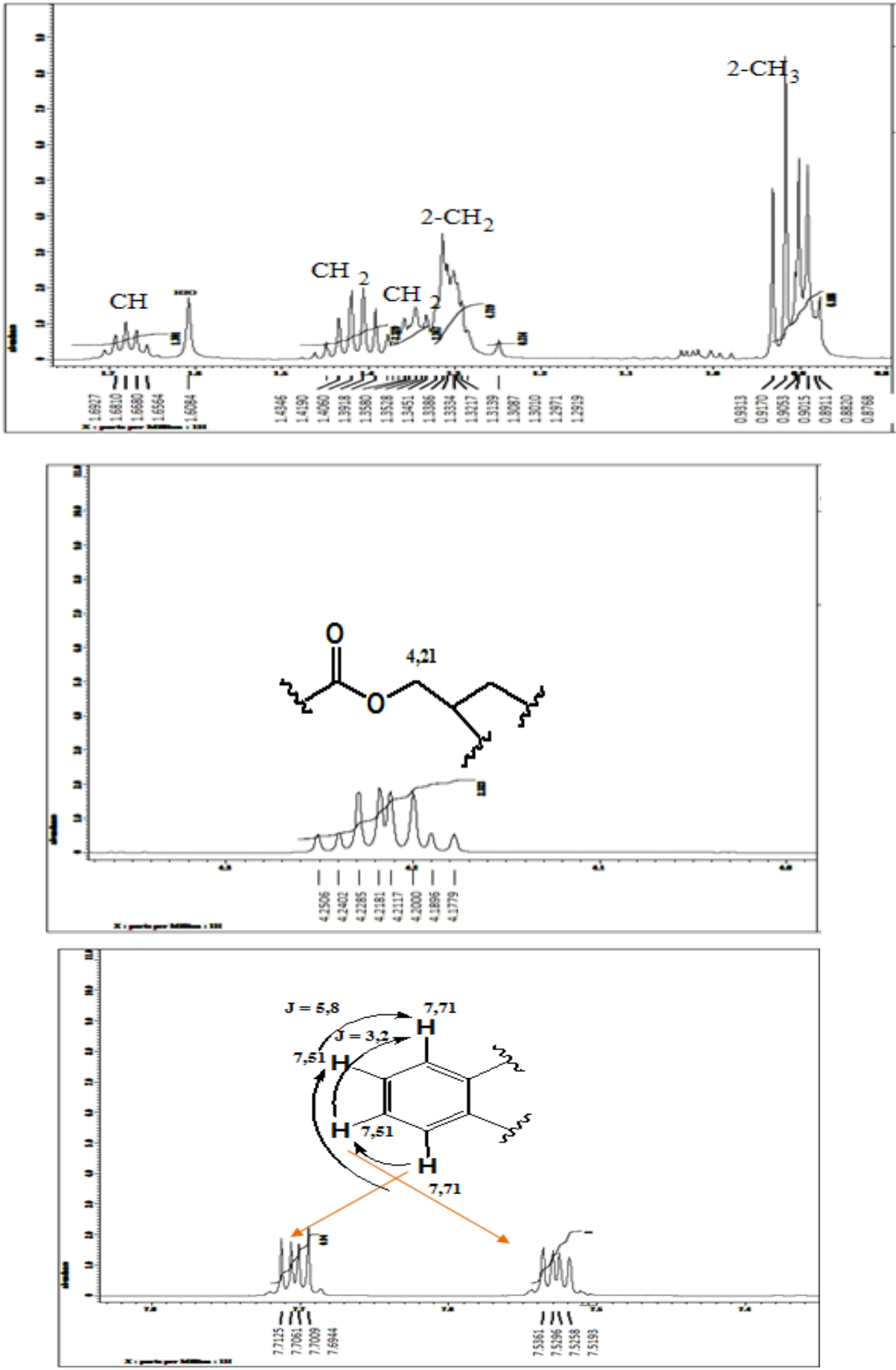

Gambar 1. Penggalan spektrum ${ }^{1} \mathrm{H}-\mathrm{NMR}$ senyawa hasil isolasi pada $\delta_{\mathrm{H}} 0,90-1,69 \mathrm{ppm}$ (A) $, \delta_{\mathrm{H}} 4,2 \mathrm{ppm}(\mathrm{B})$ dan $\delta_{\mathrm{H}} 7,51-7,71 \mathrm{ppm}(\mathrm{C})$ 
Pada spektrum ${ }^{1} \mathrm{H}-\mathrm{NMR}$ juga terlihat sinyal pada $\delta_{\mathrm{H}} 4,21 \mathrm{ppm}(2 \mathrm{H}, m)$ yang menunjukkan adanya gugus $\mathrm{CH}_{2}$. Pada $\delta_{\mathrm{H}} 4,21 \mathrm{ppm}$ ini merupakan sinyal yang khas untuk gugus $\mathrm{CH}_{2}$ yang terikat dengan heteroatom yaitu atom $\mathrm{O}$ dalam bentuk ester dan mempunyai proton tetangga dalam bentuk rantai alifatik. Selanjutnya juga terlihat adanya sinyal pada daerah $\delta_{\mathrm{H}} 7,51 \mathrm{ppm}$ dan $\delta_{\mathrm{H}} 7,71$ $\operatorname{ppm}(2 \mathrm{H}, d d, J=3,20 ; 5,82 \mathrm{~Hz})$. Kedua sinyal proton tersebut karakteristik untuk proton aromatik yang terkopling orto.
Masing-masing proton muncul sebagai sinyal doublet - doublet, sehingga diduga kedua proton tersebut dibelah oleh dua buah proton tetangga yang berbeda lingkungan kimianya.

Data spektrum ${ }^{1} \mathrm{H}-\mathrm{NMR}$ ini selanjutnya dibandingkan dengan data pembanding bis(2-etilheksil)ftalat yang telah dilaporkan sebelumnya dari jamur endofitik Aspergillus $\mathrm{sp}_{1}$ batang tumbuhan brotowali (Tinospora crispa) (Elfita dkk., 2013b)

Tabel 1. Perbandingan data ${ }^{1} \mathrm{H}-\mathrm{NMR}$ untuk senyawa hasil isolasi dengan pembanding bis(2-etilheksil) (Elfita et. al., 2013b)

\begin{tabular}{|c|c|c|c|}
\hline No C & $\begin{array}{c}\delta_{\mathrm{C}}(\mathbf{p p m})^{*} \\
\text { pembanding }\end{array}$ & $\begin{array}{c}\delta_{\mathrm{H}}(\mathrm{ppm})^{*} \\
\text { pembanding }\end{array}$ & $\begin{array}{c}\delta_{H}(p p m) \text { senyawa } \\
\text { hasil isolasi }\end{array}$ \\
\hline 1 & 132,2 & & \\
\hline 2 & 130,7 & $\begin{array}{l}7,70(1 \mathrm{H}, d d, J= \\
3,5 \text { dan } 5,5 \mathrm{~Hz})\end{array}$ & $\begin{array}{l}7,71(1 \mathrm{H}, d d, J=3,20 \\
\text { dan } 5,82 \mathrm{~Hz})\end{array}$ \\
\hline 3 & 128,7 & $\begin{array}{l}7,51(1 \mathrm{H}, d d, J= \\
3,5 \text { dan } 5,5 \mathrm{~Hz})\end{array}$ & $\begin{array}{l}7,51(1 \mathrm{H}, d d, J=3,20 \\
\text { dan } 5,82 \mathrm{~Hz})\end{array}$ \\
\hline 4 & 167,6 & - & - \\
\hline $1^{\prime}$ & 67,9 & $4,23(2 \mathrm{H}, m)$ & $4,21(2 \mathrm{H}, m)$ \\
\hline 2 ' & 38,6 & $1,69(1 \mathrm{H}, m)$ & $1,69(1 \mathrm{H}, m)$ \\
\hline $3^{\prime}$ & 28,8 & $1,33(2 \mathrm{H}, m)$ & $1,34(2 \mathrm{H}, m)$ \\
\hline $4^{\prime}$ & 23,6 & $1,33(2 \mathrm{H}, m)$ & $1,33(2 \mathrm{H}, m)$ \\
\hline 5 & 22,9 & $1,32(2 \mathrm{H}, m)$ & $1,32(2 \mathrm{H}, m)$ \\
\hline 6 & 10,8 & $0,91(3 \mathrm{H}, t)$ & $0,90(3 \mathrm{H}, t)$ \\
\hline $7^{\prime}$ & 30,3 & $1,38(2 \mathrm{H}, m)$ & $1,39(2 \mathrm{H}, m)$ \\
\hline 8, & 13,9 & $0,91(3 \mathrm{H}, t)$ & $0,90(3 \mathrm{H}, t)$ \\
\hline
\end{tabular}

Berdasarkan data pada Tabel 1 terlihat senyawa hasil isolasi memberikan nilai pergeseran kimia hidrogen dan karbon yang mirip dengan data pembanding bis(2-etilheksil)ftalat yang dilaporkan dari jamur endofitik tumbuhan brotowali (Elfita dkk., 2013b). Berdasarkan analisis data spektroskopi NMR 1D serta data pembanding yang digunakan maka diusulkan senyawa hasil isolasi adalah bis(2-etilheksil)ftalat dengan struktur molekul senyawa tersebut seperti ditunjukkan pada Gambar 2.<smiles>CCCCC(CC)COC(=O)c1ccccc1C(=O)OCC(CC)CCCC</smiles>

Gambar 2. Struktur senyawa hasil isolasi

\section{Uji Aktivitas Antioksidan dengan Metode DPPH}

Uji aktivitas antioksidan dari senyawa uji dilakukan menggunakan me- 
tode DPPH. Metode ini didasarkan pada kemampuan dari zat antioksidan dalam menetralkan radikal DPPH, dengan menyumbangkan protonnya sehingga membentuk radikal yang lebih stabil.

Nilai aktivitas dinyatakan dalam persen inhibisi (\%I). Hubungan aktivitas peredaman radikal DPPH dari senyawa hasil isolasi dan senyawa standar (vitamin C pada berbagai konsentrasi (1000, 500, $250,125,62,5 ; 31,25 ; 15,625 ; 7,81 \mu \mathrm{g} / \mathrm{mL})$ yang dinyatakan dalam \% inhibisi dapat dilihat pada Tabel 2. Data pada Tabel 2 menunjukkan senyawa uji dan senyawa antioksidan standar mempunyai aktivitas peredaman (\%) terhadap radikal DPPH dengan kekuatan serapan yang berbeda. Peningkatan konsentrasi senyawa uji meningkatkan nilai \% inhibisi terhadap radikal DPPH. Pada konsentrasi yang sama senyawa hasil isolasi menunjukkan aktivitas lebih rendah dibandingkan senyawa antioksidan standar asam askorbat. Efektifitas peredaman radikal DPPH ditentukan dengan menghitung nilai $\mathrm{IC}_{50}$ melalui perhitungan regresi linier, yaitu konsentrasi dari senyawa uji yang dapat meredam 50\% radikal DPPH. Nilai $\mathrm{IC}_{50}$ dari senyawa uji dan senyawa antioksidan standar terhadap peredaman radikal DPPH dihitung dengan persamaan regresi melalui hubungan antara konsentrasi dengan persen inhibisi. Berdasarkan persamaan regresi diperoleh nilai $\mathrm{IC}_{50}$ senyawa hasil isolasi adalah 232,9 $\mu \mathrm{g} / \mathrm{mL}$, sedangkan standar antioksidan vitamin $\mathrm{C}$ menghasilkan $\mathrm{IC}_{50}$ sebesar $12,77 \mu \mathrm{g} / \mathrm{mL}$.

Tabel 2. Nilai absorbansi dan \% Inhibisi dari senyawa hasil iolasi dan senyawa standar.

\begin{tabular}{ccccc}
\hline \multirow{2}{*}{ Konsentrasi } & \multicolumn{2}{c}{ Absorbansi rerata } & \multicolumn{2}{c}{$\%$ Inhibisi } \\
\cline { 2 - 5 } & Senyawa uji & Vitamin C & Senyawa uji & Vitamin C \\
\hline 1000 & 0,313 & 0,017 & 57,10 & 97,66 \\
500 & 0,361 & 0,031 & 50,48 & 95,75 \\
250 & 0,362 & 0,085 & 50,35 & 88,34 \\
125 & 0,371 & 0,159 & 49,11 & 78,19 \\
62,5 & 0,380 & 0,181 & 47,87 & 75,17 \\
31,25 & 0,430 & 0,218 & 41,10 & 70,10 \\
15,625 & 0,445 & 0,349 & 38,96 & 52,13 \\
7,8125 & 0,446 & 0,408 & 38,82 & 44,03 \\
\hline
\end{tabular}

Berdasarkan standar tingkat aktivitas antioksidan yang dikemukakan oleh Minami et al (1998) senyawa yang termasuk kategori sangat aktif memiliki nilai $\mathrm{IC}_{50}<10 \mu \mathrm{g} / \mathrm{mL}$, kategori aktif bila memiliki nilai $\mathrm{IC}_{50} 10-100 \mu \mathrm{g} / \mathrm{mL}$, dan nilai $\mathrm{IC}_{50}>100 \mu \mathrm{g} / \mathrm{mL}$ dikategorikan tidak aktif. Berdasarkan kategori ini maka senyawa uji dikategorikan tidak aktif sebagai antioksidan.

\section{KESIMPULAN}

1. Senyawa metabolit sekunder berupa minyak berwarna kuning $(0,12 \mathrm{~g})$ telah berhasil diisolasi dari ekstrak $n$-heksana batang brotowali dan berdasarkan analisis spektrometri NMR 1D dan dengan membandingkan data pada literatur disimpulkan senyawa hasil isolasi memiliki kemiripan dengan Bis (-2-etilheksil)ftalat.

2. Uji aktivitas antioksidan dari senyawa murni hasil isolasi dengan metode DPPH menunjukkan IC $_{50} 232,9 \mu \mathrm{g} / \mathrm{mL}$ dan dikategorikan tidak aktif sebagai antioksidan

\section{DAFTAR PUSTAKA}

Elfita, Muharni, Munawar, Legasari, L., and Darwati. 2011. Antimalaria Compounds from Endophytic Fungi of Brotowali (Tinospora 
crispa L). Indoneisian Journal of Chemistry. 11(1): 53-58.

Elfita, Munawar, Muharni, and Suprayetno. 2013a. New Pyran of An Fungus Fusarium sp Isolated from The Leaves of Brotowali (Tinaspora crispa). Indonesian Journal of Chemistry. 13(3):209215.

Elfita, Munawar, Muharni, and Wahyuni, S. 2013b. Isolasi Senyawa Metabolit Sekunder Turunan Ftalat dari Jamur Endofitik Tumbuhan Brotowali (Tinospora crispa L). Seminar Nasional Biodiversitas, 09 November 2013, Solo.

Elfita, Munawar, Muharni, and Sudrajat, M.A. 2014. Identification of New Lactone Derivatives Isolated from Trichoderma sp., An Endophytic Fungus of Brotowali (Tinospora crispa). Hayati Journal of Bioscience. 21 (1), 15-20) .

Fukuda, N., Yonemitsu, M., and Kimura, T. 1983. Studies on the Constituents of the Stems of Tinospora tuberculata Bemuee.I.NTrans-and N-Cis Feruloyl Tiramine, and a New Phenolic Glucosida Tinotuberide. Chemical \&Pharmaceutical Bulletin. Volume 3, 156-161.

Fukuda, N., Yonemitsu, M., Kimura, T. 1985. Studies on the constituents of the stems of Tinospora tuberculata Beumee. II. New diterpenoids, borapetoside A, B, C and borapetol A. Chemical \&Pharmaceutical Bulletin. 33(10): 4438- 4444.

Guo, Y., Kojima, K., Lin, L., Fu, X., Zhao, C., Hatano, K., Chen, Y.J., and Ogihara, Y. 1999. A New NMethyltetrahydroprotoberberine Alkaloid from Tinosporahainanensis. Chemical \& Pharacuetical Bulletin. 47(2) : 287-289.

Hatthakitpanichakul, S. 2001. Isolation and Synthesis of Active Substances with Cardiac Contractility from
Tinospora crispa Miers. A Thesis submitted in Partial Fulfillment of the Requirements for the Degree of Master of Science (Chemistry) Graduate School, Kasetsart University.

Irianti, T., Puspita, S., dan Suryani, E. 2011. Aktivitas Penangkapan Radikal 2,2-Difenil-1-Pikrilhidrazil Oleh Ekstrak Etanolik Batang Brotowali (Tinospora Crispa(L.) Miers) dan Fraksi-Fraksinya. Majalah Obat Tradisional, 16(3), $138-144$

Kamarazaman, I.S., Amom, Zulkhairi, HJ., Ali, R.M., Akim, A.MD., Azman, K.F., Arapoc, D.J., Hassan, M.K.N., Arshad, M.S.M, Shah, Zamree.Md., and Kadir, K.K.A. 2012. Inhibitory Properties of Tinospora crispa Extracs on TNF $\grave{\alpha}$ Induced Inflammation on Human Umbilical Vein Endothelial. International Journal of Tropical Medicine. 7 (1): 24 - 29.

Minami, H., Hamaguchi, K., Kubo, M., and Fukuyama, Y. 1998. Phytochemistry, 49(6): 1783-1785.

Noor, $\mathrm{H}$ and Aschroft, S.J. 1998.Pharmacological Characterization of The Antihyperglycaemic Properties of Tinospora crispa Extract. Journal of Ethnopharmacology; 62(1): 7-13

Santa, I.G.P., dan Bambang, P.E.W. 1998. Studi Taksonomi Brotowali (Tinospora crispa L Miers) Ex Hook $\mathrm{F}$ and Thoms. Warta Tumbuhan Obat Indonesia, 4(2) : $27-30$.

Zambrut, A. A., Desy, M. G., andHusni, M. M. 1999. Aktivitas Antimalaria Senyawa Tinokrisposid secara in vivo. Cermin Dunia Kedokteran. ISSN : 0125-913X. 